\title{
O ENSAIO LITERÁRIO NO BRASIL DE ALEXANDRE EULALIO E A REVISTA DO LIVRO
}

\author{
Silvia Quintanilha Macedo \\ s.quintanilha@ig.com.br
}

\section{APRESENTAÇÃO}

É de Benedito Nunes a referência sobre a importância de Alexandre Eulalio no campo da história da literatura, conferida pela pesquisa realizada sobre o ensaísmo literário brasileiro: "Mas a crítica, que já ganhara, em definitivo, um vulto de ensaísmo humanístico, começando a bem escrever nos ensaios de Alexandre Eulalio-o mais notável sobre $O$ ensaio literário no Brasil (NUNES, 200o, p.68).

O ensaio literário no Brasil (1962) constitui um "panorama crítico evolutivo de 150 anos da nossa prosa de não-ficção" (CALIL, 1993, p. 326). Ilustra a origem jornalística do ensaísmo brasileiro e sua vocação de misturar-se ao fazer histórico do país, orientando-se segundo o sentido largo que se depreende do gênero em questão.

"Prosa literária cultivada" ou "livre comentário estético", ambas as definições servem de base para o crítico registrar os diferentes momentos da história política, social e cultural brasileira, através dos escritos de numerosos autores. Na seleção dos dados que tem pela frente, o estudioso combina o domínio de informação, a análise das diferentes tendências e modalidades assumidas pelos textos de cada época e a distinção da força que o estilo exerce sobre as idéias. Alexandre Eulalio acaba por estabe- 
lecer um quadro bastante preciso, detalhado e vivo, embora circunscrito a um plano de síntese absoluta, das ideias político-culturais brasileiras dos séculos XIX e XX.

Armando uma estratégia de análise em que os momentos decisivos integram também colaborações de menor porte, o estudo se faz através dessa dialética, em que a história do ensaio brasileiro aparece como resultado de uma ampla e diversificada realização. Incluem-se, no conjunto, inúmeras contradições de tons, estilos, tendências, manifestações, que entretanto têm em comum o peso determinante das condições concretas do tempo.

O ensaio literário no Brasil reforça a tese segundo a qual a compreensão histórico-literária anima a reflexão do crítico diamantino. Serve inclusive para ilustrar o conceito de história da literatura que Antoine Compagnon estabelece

\footnotetext{
uma soma, um panorama, uma obra de vulgarização e, o mais das vezes, não é uma verdadeira história, senão uma sucessão de monografias sobre os grandes escritores e os menos grandes, apresentados em ordem cronológica, um "quadro", como se dizia no início do século XIX. (COMPAGNON, 2001, p. 199-200).
}

Outro trabalho realizado posteriormente aponta para a mesma direção, isto é, tem a mesma vocação panorâmica do estudo anterior, embora voltado para matéria diversa. Estamos nos referindo ao ensaio "A Literatura em Minas Gerais no século XIX”, apresentado no III Seminário sobre a cultura mineira - século XIX em Belo Horizonte e publicado dois anos mais tarde, em 1982.

João Luiz Lafetá atua como debatedor e faz um registro admirável da capacidade que Alexandre Eulalio tem de acumular dados histórico-culturais com um espírito de abrangência e minúcia que deixou o debatedor "assustado e um pouco soterrado. Erudição espantosa, de datas, fatos, obras e autores”. (LAFETÁ, 1992, p.127).

Nessa intervenção, João Luiz Lafetá salienta, no estudo de Alexandre Eulalio, o traçado que prioriza as grandes dimensões, sem perder de vista o pormenor. Faz então a leitura do ensaio como se tratasse de uma pintura: "painel de amplas proporções - um pouco ao gosto de certa pintura heróica do século XIX que nos atrai pela majestade da cena apresentada, mas também nos prende pelos detalhes trabalhados e minuciosos de uma ou outra passagem”. (LAFETÁ, 1992, p.126).

Ao estabelecer esta tensão entre painel e detalhe, presente nesse trabalho específico, Lafetá acaba por depreender uma linha interpretativa 
estratégica para a compreensão do pensamento crítico de Alexandre Eulalio. Nesse sentido, a conclusão desse comentário é particularmente esclarecedora: "Se há a linha horizontal que persegue cem anos de história literária, há também algumas linhas verticais, cortes em profundidade, que pescam e exibem com mais profundidade algum personagem do painel”. (LAFETÁ, 1992, p. 126).

A esse segundo momento, referente ao mergulho vertical, Lafetá denomina de "síntese fulgurante" capaz de trazer à tona uma idéia ou personagem apreendidos "com traço fino, sempre penetrante", o que permite destaque "da massa mais ou menos indistinta da composição global”. (LAFETÁ, 1992, p.126).

Voltando à classificação que Antoine Compagnon formula em $O$ demônio da teoria, há duas distinções correspondentes ao conceito de história literária, a primeira delas de sentido amplo e a outra de sentido mais restrito. Vista em seu sentido amplo, a história literária equivale ao estudo erudito sobre a literatura; um ramo da filologia, ocupado pela reconstrução histórica de uma época; uma arqueologia da linguagem, da literatura e da cultura em geral. Em sentido restrito, a filologia é entendida modernamente como gramática histórica, como estudo histórico de uma língua.

"A hipótese central da história literária é que o escritor e sua obra devem ser compreendidos em sua situação histórica, que a compreensão de um texto pressupõe o conhecimento de seu contexto". (COMPAGNON,1998, p.201).

\section{Modalidades do ensaio literário brasileiro}

O ensaio literário no Brasil pode de fato se revelar como um ideário que ajuda a definir a pesquisa realizada por Alexandre Eulalio na Revista do Livro, devido à prioridade que ela concede à prática do gênero ensaístico ligado à literatura.

O estudo chama atenção para outros aspectos, além do caráter histórico-literário que tão bem traduz a maneira própria do autor conduzir a reflexão crítica. O conceito de "prosa literária cultivada" ou "livre comentário estético" dá a medida do sentido amplo que o conceito de ensaio assume, ao lado de tendências e modalidades ensaísticas que tanto interesse despertam ao longo da trajetória intelectual de Alexandre Eulalio.

Vale, portanto, conferir como algumas dessas manifestações presentes em $O$ ensaio literário no Brasil, ganham um desenvolvimento 
maior, conforme aparecem publicadas na Revista do Livro por Eulalio, escolhas entre as quais se destaca Epístolas a Irzerumo: "propõe-se ela ao modo de discursos éticos, muito em favor no período; ao jeito prestigioso de correspondência pedagógica, perfaz o roteiro utópico da educação ideal" (EULALIO,1992,p.21). As epístolas de Sousa Caldas, datadas de 1812 e 1813, "tratam de aspectos cruciais da questão máxima das Luzes: liberdade, tolerância, educação, convívio social” (EULÁLIO, 1992, p.21).

Outra modalidade ensaística, o folhetim, define-se segundo o estudo em questão como uma das "suas tendências extremas de quase ficção ou quase política”, surgida na altura da década de 1830. Trata-se de uma "nova espécie jornalística", grafada no Jornal do Comércio da Corte, "debaixo dos títulos variedade, literária, apêndice". Mais adiante, o folhetim recebe outra definição: "comentário sem maiores compromissos de acontecimentos e episódios", "crônica de variedades - ora a nota de costumes e a descrição de tipos, ora a fantasia apologal ou a polêmica moralizadora" (EULALIO, 1992, p.29).

O autor recorre a Brito Broca, para quem no folhetim "Tratava-se, em última análise, de um noticiário submetido a um tratamento literário. $\mathrm{O}$ cronista percorria os assuntos, discutindo-os como homem de espírito". Continuando com Brito Broca, os "folhetinistas 'entremeavam geralmente os flagrantes de costumes com os comentários políticos, a crítica da última peça representada, ou as mais recentes notícias do Estrangeiro'” (EULALIO,1992, p.29).

Embora o desenvolvimento da imprensa organize-se em torno do noticiário político, abre-se espaço para a literatura amena, cujo traço alusivo, disfarça "de maneira mais ou menos alegórica os acontecimentos políticos. Literatura que por isso não precisa ser à clef, mas não abdica dos gêneros alusivos" (EULALIO, 1992, p.28-29).

Na Revista do Livro, Alexandre Eulalio se ocupará de folhetins, em função do caráter de variedades do gênero, "que realizará uma autêntica catalogação de tipos e situações da vida cotidiana", "caminhando para uma análise severa da sociedade circunstante", como adianta em $O$ ensaio literário no Brasil. É o caso, por exemplo de "um Celso Magalhães no rodapé de O País, do Maranhão, em idos de 1870" (EULALIO,1992, p.33).

A fim de melhor compreender a importância da pesquisa dos folhetins, na Revista do Livro, deve-se associá-la à recuperação dos jornais, bastante expressiva no trabalho de Alexandre Eulalio como editor da publicação do Instituto Nacional do Livro. Portanto, a difusão do gênero acontece graças ao desenvolvimento da imprensa, que a partir de 1830 toma "marcado sabor literário", incorporando "as mais diferentes opor- 
tunidades de se experimentar: crônica das novidades do dia, críticas de livro, de ideias; política, música, artes plásticas, teatro - tudo encontra lugar na folha". O campo de publicação se estende às revistas, como é o caso da Nyteroy (EULALIO.1992, p.40).

A difusão do folhetim romântico deve-se à abertura do jornal novecentista para o público feminino, que agora pede "redator especializado e rodapé apenas seu, até mesmo nos grandes diários”. Exigente de um "caráter mais íntimo, em tom faceto e desenfadado", o folhetim romântico espera dos cronistas o registro e comentário de "todos os acontecimentos da atualidade mundana, numa prosa que procura abrir o seu caminho dentro dos meandros da fantasia daqueles que escrevem" (EULALIO,1992,p.31-32).

Criação do romantismo, o folhetim continua seu desenvolvimento durante o Realismo, e ainda com o simbolismo. "Exigindo, vivacidade e graça, precisão e fantasia”, alcança forma esgarçada, ao se "dissolver no pontilhismo de sensações vagas e experimentação expressiva fronteiriça ou anexa à prosa poética simbolista" (EULALIO,1992,P.34).

"Outro modo pelo qual a crítica vai se manifestar, e com maior vivacidade, será através de polêmicas literárias". Trata-se de "verdadeiras batalhas campais", capazes de transmitir "inusitada vivacidade a um ambiente sempre tão insensível à coisa literária". O sensacionalismo e o escândalo próprios do gênero, "têm a vantagem de colocar os assuntos artísticos na ordem do dia", além de colaborar "de modo tortuoso para a explicitação dos problemas estéticos", pois se revela como "espécie dialética do ensaio crítico, diálogo veemente que se encaminha para a sátira"(EULÁLIO,1992,p.41-42).

Cabe ainda destacar a conferência literária: "Ao lado da crônica e da reportagem é cultivado também um outro gênero menor que (...) empolga de modo mais completo agora o público do tempo", "primeira década republicana", que se entusiasma pelo "ensaio quase sempre frívolo,variação palavrosa diante de algum tema genérico, vago, efêmero". A conferência, recolhida em livro, representa "fenômeno inseparável do período". Eulálio cita Brito Broca, a propósito da designação "prosa parnasiana", cunhada pelo amigo, em virtude da natureza estética "gratuita", pelo efeito "ornamental", da "frase alambicada", semelhante "aos sonetos da escola: polidos, sensíveis, encantadores, vazios. Decorativos e incômodos como o febril bric-à-brac esmagador das casas de então"(EULALIO,1992,p.54).

A sátira, "gênero híbrido", recolhe elementos da "literatura panfletária”, da crônica fantasista e do "apólogo moralizante". (EULALIO, 1992, p. 
38). "Espinha dorsal de toda essa literatura", que conquista sempre maior consciência de missão, é sem dúvida a Crítica". Vem do Romantismo o compromisso de "reformar o país conforme o ponto de vista das letras", o que obriga a crítica a priorizar o "campo da exposição e divulgação das ideias" em detrimento do "campo criativo"(EULALIO, 1992, p.39).

Eulalio ainda menciona as revistas das sociedades acadêmicas, e a ação dos grêmios literários, ambos vinculados ao ensino superior, aos quais se deve grande incentivo à prosa ensaística. Entre os devotos do culturalismo de Tobias Barreto, Sílvio Romero "há de ser o grande coordenador de nossa cultura. Não que fosse o único, pois "As décadas de 70 e 80 assistiram também à estreia de figuras do porte de Joaquim Nabuco, Rui Barbosa, Capistrano de Abreu, Araripe Júnior, Carlos de Lae, José Veríssimo, Eduardo Prado(...)" (EULALIO, 1992, p. 43-45).

Na sequência, o estudo discute o "Problema da 'arte de escrever", momento de reação ao "desalinho romântico", quando o "ensaio no Brasil tenta reformular a sua expressão". Concorre para a tarefa, "a marca inconteste da prosa de além mar", uma decorrência das "grandes presenças dos portugueses na nossa imprensa - Eça de Queirós, Ramalho Ortigão”. Entretanto, a renovação da língua exige sutileza e encontrará os "cultores da medida e da contenção urbana". "Mestre insuperável no gênero, Machado de Assis contará com seguidores dessa vertente" (EULALIO, 1992,p.48-49).

Para o recorte do qual nos valemos, três outras questões inscritas no estudo de Alexandre Eulalio são obrigatórias, conforme exemplificam os tópicos "Ensaísmo, articulismo", que existem de "modo fundamental nas folhas", sob "a forma obrigatória de colaboração para a imprensa"(EULALIO, 1992, p.50). Em "Revistas, quase sempre", o autor confere à queda da Monarquia uma força que foi capaz de afirmar "algumas das nossas melhores vocações ensaísticas", diante da necessidade de analisar as circunstâncias históricas do momento. A Revista Brasileira reuniu os prosadores das diversas correntes para as quais convergiam as atividades intelectuais do país (EULALIO, 1992, p.51-52).

"Também a Revista do Brasil, sob a direção de Monteiro Lobato, em certo período também Paulo Prado, representará de modo todo panorômico a mentalidade brasileira". Mais precisamente, a luta dos intelectuais insatisfeitos com "a realidade presente, pretendendo agir de modo concreto no campo cultural” (EULALIO,1992,p.56-57).

Finalmente, o terceiro tópico, "A tradição da crônica", avalia o modo pelo qual continua a existir o "único gênero (...) que acompanha o gosto do público sem perder a qualidade literária, e, ao contrário, em cada situação nova recria essa qualidade". De acordo com o crítico, "a tradição 
brasileira do familiar essay persistia muito viva depois de João do Rio, Bilac, Raimundo Correia, Guimarães Passos, Artur Azevedo, Coelho Neto". No entanto, tais cronistas continuam a escrever de maneira tradicional, não incorporando "a inovação da reportagem lírica, essa grande contribuição de João do Rio ao gênero já então algo estafado”(EULALIO,1992, p.6o).

\section{O ensaio literário visto a partir da Revista do Livro}

A segunda parte desse trabalho pretende recuperar o aparecimento na Revista do Livro, dos diferentes gêneros ensaísticos tratados por Alexandre Eulalio em $O$ ensaio literário no Brasil. Conforme se constatará a seguir, permanece linha interpretativa semelhante àquela que orienta as escolhas editoriais do crítico diamantino na direção da revista.

Outras modalidades ensaísticas, como correspondência e diário foram incluídas, por revelarem traços característicos da "prosa literária amena" que definem as modalidades, conforme as descreve a segura pesquisa do autor

\section{RECONSTITUIÇÃO HISTÓRICA}

\section{Um polemista surge de "Os Folhetins de Hop-Frog", texto de Ale- xandre Eulalio em colaboração com Brito Broca}

Os "Folhetins de Hop-Frog" abordam a trajetória de um jovem escritor, bastante típica em nossa vida literária dos novecentos. Isso porque o retratado, Tomás Alves, estudante de medicina, aproxima-se da literatura através das rodas boêmias, vendo nela, como muitos de sua geração, aquilo que os articulistas denominam como second métier. A introdução do ensaio dá conta desse traço constitutivo da intelectualidade brasileira do século passado, chamando atenção para o grande poder de influência dos círculos boêmios, responsáveis não só por alimentar vocações, mas também por dirigir o debate.

Tomás Alves foi escolhido pelo jornalista Ferreira de Araújo para responder a Camilo Castelo Branco que, em seu Cancioneiro Alegre, atacara poetas brasileiros. A polêmica projeta o literato iniciante e retém a atenção dos ensaístas, servindo para demonstrar o valor por eles atribu-

1 Rio de Janeiro, n. 14, jun.1959, p.125-17o. 
ído às questões periféricas e paralelas relativas ao ambiente que cerca os artistas.

A ênfase nos desdobramentos envolvendo os polemistas, os daqui e o de lá, denuncia a curiosidade dos editores pelos fatos de nossa vida cultural. Isso significa dizer que importa aos analistas, no momento de estabelecer as prioridades de seu estudo, enfocar certos episódios, principalmente aqueles relacionados aos acontecimentos pouco divulgados, ou até então considerados de pouca relevância, como bem exemplifica a polêmica entre Camilo e os dois jovens intelectuais brasileiros, estes últimos praticamente desconhecidos atualmente.

Instiga a dupla de pesquisadores não só o caráter de testemunho, desempenhado pelo Cancioneiro Alegre, das disputas entre os intelectuais nativos e os da antiga metrópole. Também conta para esses dois colecionadores de documentos o folheto de oito páginas assinado por Tomás Alves, "verdadeira raridade bibliográfica", o mesmo ocorrendo com o texto do outro polemista do caso, Artur Barreiros.

A colaboração de Brito Broca como co-autor naturalmente se mostra fundamental, sobretudo na ênfase dos acontecimentos que marcam a vida literária. Esse traço persiste conforme se desenvolve o episódio do desagravo, que termina por levar Tomás Alves a assumir papel de destaque como colaborador na Gazeta de Notícias, atividade que exerce junto a um elenco da maior representatividade no cenário cultural do momento entre as quais Eça de Queirós, Machado de Assis, Raul Pompéia e Araripe Júnior.

A fim de justificar a publicação dos "Folhetins de Hop-Frog"2, os editores lembram que a obra é considerada como manifestação pioneira do nosso Naturalismo. Conferir, portanto, a dimensão exata desse pioneirismo define a linha argumentativa adotada na parte final do artigo, atitude que busca sem dúvida recuperar a figura de Tomás Alves, reservando-lhe um lugar na historiografia literária brasileira.

De acordo com tal perspectiva, repete-se outro tema de interesse que une Alexandre Eulalio e Brito Broca. Além do estudo cerrado das pequenas circunstâncias históricas e da vida literária - aspecto determinante desse artigo sobre Hop-Frog - a busca de reconhecimento para autores de menor relevo cumpre certamente o programa que Alexandre, inspirado no amigo, imprime na sua participação como redator da Revis-

2 "Na Gazeta de Notícias [Tomás Alves] iniciou a colaboração a 17 de novembro de 1879, com a narrativa "Velha História”. No corpo do jornal vinha a seguinte nota: 'Publicamos hoje em folhetim um pequeno conto realista, de um escritor moço mas já bastante conhecido e apreciado,Hop-Frog"” (EULALIO, 1959, p.126). 
ta do Livro. A parceria autoral nesses "Folhetins de Hop-Frog" só confirma a linha programática adotada.

Apoiando-se no critério estabelecido por Lúcia Miguel Pereira, de acordo com o qual a influência de Eça e Zola sobre a literatura brasileira manteve-se forte durante os vinte anos finais do século XIX, Alexandre Eulalio conclui: "Nesse caso podemos dizer que Tomás Alves se não foi propriamente o nosso primeiro naturalista, foi o primeiro a anunciar o Naturalismo brasileiro com os tiques e modismos que nele iriam predominar". (EULALIO, 1959, p.127).

De acordo com esse enfoque, Alexandre Eulalio e Brito Broca atingem o objetivo de conquistar uma posição dentro da historiografia literária brasileira para uma obra, e reconhecem autores de valor literário duvidoso, quer se examine o estilo, ou a construção das personagens, das cenas e da escolha vocabular.

O texto finaliza com a retomada de aspectos biográficos, confirmando a tendência já anunciada logo de início sobre o exercício da literatura como o second metier: Tomás Alves, já médico em Campinas, colabora apenas esporadicamente nos jornais daquela cidade. Outras observações dão conta, bem ao gosto do colecionador de pequenas informações e notícias, do interesse manifestado por João Ribeiro pela pesquisa folclórica que Tomás Alves deixou registrada anonimamente.

\section{Sátira}

Com As páginas do ano $2000^{3}$, de Joaquim Felício dos Santos, o trabalho do editor literário resume-se em grande parte à reconstituição histórica, dessa que é "talvez a mais longa e uma das mais violentas sátiras políticas escritas no reinado de Pedro. II” (EULALIO,1957, p.103).

No ponto de partida do ensaio deve estar o reconhecimento de que é relativo o acabamento da obra, mas, por isso mesmo, importa destacá-la, considerando seu caráter apressado, semi-inédito, perdida em um jornal provinciano de meados do século XIX; no caso de Joaquim Felício, O Jequetinhonha, entre 1861 e 1864. Não escapa a Alexandre Eulalio a originalidade dessas "infinitas aventuras de um Júlio Verne sertanejo", nem a festejada recepção do público local.

Paralelamente à inflamada linha editorial de O Jequetinhonha, a evolução dos acontecimentos políticos ganha também essa versão folhetinesca, destinada a divertir, mas sem dúvida a castigar. 
O valor histórico, de cópia satírica que detalha os acontecimentos da época, tem sua dimensão reconhecida pelo crítico, que procura ver, na narrativa oscilante diante da evolução dos acontecimentos, uma finura de traço capaz de superar, ou colorir melhor o panfleto político.

$\mathrm{O}$ editor explica as duas fases que constituem o folhetim. A primeira refere-se à "crônica dos acontecimentos do reinado sob o ponto de vista do futuro" e, Alexandre completa, "do ponto de vista dos liberais exaltados de 68”. (EULALIO, 1957, p.104). Nela se incluem revelações espantosas, entre as quais episódios da Guerra do Paraguai e da reunião do ministério recém-empossado. Aqui, reconhece o crítico, apesar das qualidades da sátira e do poder inventivo da "história secreta", o resultado beira a monotonia. A segunda parte revela maior ação, humorismo e ironia no tratamento dispensado à viagem que o Imperador realiza ao século XXI, conduzida por um médium.

A leitura de Eulalio detém-se nos acontecimentos históricos que são o núcleo de As páginas do ano 200o. Aborda a Grande História e a Pequena História, examinando nesta as repercussões da sátira feliciana no cenário político do Império, fonte de pesquisa miúda da qual não se furtará o ensaísta.

Mesmo atento à produção cultural de caráter provinciano, o crítico não perde nunca de vista o cânone, sobretudo quando é necessário estabelecer as fontes e influências. Joaquim Felício dos Santos, por exemplo, figura como leitor do romantismo francês, mas "numa biblioteca onde a maioria dos livros era do século XVIII".

\section{Conferência}

Outro artigo de Alexandre Eulalio na Revista do Livro, "Oliveira Lima e Machado de Assis"4, prende-se ao "indiscutível valor histórico" que a conferência de Oliveira Lima representa: o documento figura como "crítica lúcida numa época de poucos estudos sobre Machado de Assis". (EULALIO, 1957, p.169).

O texto estabelece as circunstâncias históricas envolvendo o próprio documento e detalhes da realização do evento. Dentro desse plano, são mencionados o local e a data da conferência (na Sorbonne, em abril de 1909); a presidência da seção, a cargo de Anatole France; a versão em português que aparece no ano seguinte publicada no Jornal do Comércio; e, finalmente, a referência sobre a condição de raridade bibliográfica atribuída ao original em francês. 
A publicação de "A literatura atual no Brasil”, conferência que Graça Aranha pronuncia em Buenos Aires em 1897, reflete intenção semelhante do editor: uma contribuição à história das ideias literárias. $\mathrm{O}$ documento deve servir como "depoimento da consciência crítica de um contemporâneo, em momento de grande fermentação para a nossa história literária”. (EULALIO,1961, p.172).

Às características pessoais, que dão conta de uma inteligência brilhante e precoce, soma-se a desenvoltura intelectual do conferencista no cenário cultural brasileiro do momento. As qualidades pessoais e a posição social tornam a vida de Graça Aranha paradigmática, no sentido de incorporar o perfil do jovem brasileiro, intelectualizado, rico, durante a virada do século XIX para o século XX. Obrigatoriamente, abre-se espaço para a fixação de um referencial importante no campo de investigação do pesquisador: o ambiente intelectual do qual Graça Aranha faz parte.

É possível então conferir as relações de amizade, um tema caro a nosso autor. Constitui um bom exemplo a aproximação entre José Veríssimo e Graça Aranha, este último colaborador da Revista do Brasil, levado pelas mãos do amigo mais velho e influente. Extensão desse relacionamento fraterno, a Academia Brasileira de Letras e "o espírito de tolerância do regime monárquico" compõem uma atmosfera da época, que se ajusta ao perfil do escritor maranhense.

\section{Cartas e diário de viagem}

No texto "Do arquivo de Afonso Arinos", o articulista recupera cartas que constituem "documento valioso tanto para a constituição da vida cotidiana, como para a história episódica de uma época”. (EULALIO, 1959, p.141). O valor histórico atribuído à correspondência não invalida, para Alexandre, o interesse que despertam as "impressões do antigo Tijuco onde se desenrola o drama $O$ contratador de diamantes que então escrevia“. (EULALIO, 1959, p.141). Sem contar o itinerário da própria viagem que recupera a paisagem de Diamantina em 1904. Segundo o editor, trata-se de roteiro magnífico desdobrado nas cartas e nos "sumários apontamentos de viagem", também objeto da publicação.

Nas "Cartas a Eduardo Prado"7, a história da amizade entre Eça de Queirós e Eduardo Prado, "das mais harmoniosas de que se tem notícia, na agitada república das letras brasileiras”, é vista inicialmente sob

5 Rio de Janeiro, n. 21/22, 1961, p.147-168.

6 Rio de Janeiro, n. 16, dez.1959, p.141-179.

7 Rio de Janeiro, n. 18, jun.196o, p.101-124. 
o prisma da intimidade. Alexandre Eulalio refere-se a passagens que flagram a convivência entre os dois amigos. O relato se alarga para incluir figuras históricas da política e da cultura brasileiras, representativas daquele fim de século, momento em que a "jovem república" faz barulho e causa tensão no Brasil. Figuram, como convidados de Eça, representantes de "nossa intelectualidade da belle époque", exilados políticos e "membros da nobreza imperial", além de "amigos portugueses da casa". (EULALIO, 1960, p.102).

Interessam ao ensaísta certas pequenas curiosidades, fatos engraçados, ocorrências miúdas observadas entre os frequentadores mais ou menos próximos do romancista. Outras cartas são mencionadas pelo pesquisador atento, que não deixa de comentar a biografia de Eduardo Prado, a partir de registro de seus biógrafos. O estudo visa principalmente recuperar "o nome de um autor apreciável, que não poderia ser esquecido na história de nossa cultura”. (EULALIO, 1960, p.108).

\section{Três artigos de Afonso Celso}

Com a publicação de três artigos de Afonso $\mathrm{Celso}^{8}$, a questão monárquica torna-se mais evidente, em vista do forte vínculo que prende Afonso Celso à monarquia. Os textos selecionados assumem posição abertamente partidária, de franca exaltação ao passado imperial.

Uma aura de simpatia cerca o comentário de nosso editor, principalmente levando em conta a escolha de artigos que elogiam a figura de Dom Pedro II. Para melhor defender as ideias de Afonso Celso, Eulalio cita a tese de Luís Martins, que menciona o sentimento de culpa "pela expulsão do imperador-pai e o subsequente endeusamento da república-mãe, a que sucede o 'remorso' e a 'saudade' pelo velho patriarca morto fora dos muros.” (EULALIO, 196o, p.127). O argumento de Martins serve de apoio para justificar o valor documental do texto, em vista da tensão provocada pelo assunto na época em que Afonso Celso escreveu suas reportagens.

\section{Journal de Guerre}

A publicação do Journal de Guerre", escrito por Dom Luís, o "mais ilustre dos netos do Imperador", sugere a intenção do crítico de reabilitar o nome do príncipe e manter o foco sobre a família imperial, ou sobre

8 Idem, p.127-173.

9 Rio de Janeiro, n.17, mar.196o, p.139-188. 
a monarquia, tema que frequenta os estudos publicados por Alexandre Eulalio na Revista do Livro. Vale ainda apontar a permanência no terreno do memorialismo, como igualmente ocorre com as cartas e reportagens objeto de outras edições sobre ativistas ligados à monarquia.

À imagem esportista do príncipe, cuja experiência de viagem resulta na publicação de três livros, Alexandre prefere a do soldado, no momento de estabelecer o relato de guerra como objeto da publicação. A escolha é significativa porque traduz uma imagem do nobre herói combatente, colocado, portanto, acima do homem elegante e refinado. Conta ainda o ineditismo da obra.

A apresentação encerra-se com breve comentário tecido à margem do "Journal", dando conta do ritmo narrativo e da maneira sensível do autor em captar os acontecimentos, atitude que se converte em contemplação da paisagem, ou reflexão em torno do absurdo da guerra.

\section{Cartas de Abdir a Irzerumo}

Na apresentação das "Cartas de Abdir a Irzerumo do Padre Antonio de Sousa Caldas" publicada, importante testemunho para a história das ideias, como afirma o próprio editor. Esse artigo introdutório compõe-se de duas partes. A primeira delas comenta as ideias inscritas no ensaio de Sousa Caldas, cabendo à segunda parte revelar aspectos do próprio documento, relativos ao modo pelo qual foi perdido e parcialmente recuperado.

A abertura do ensaio esclarece alguns pontos, indicando o formato das cartas, que simula uma correspondência entre dois muçulmanos. Trata-se de cinco cartas, cuja relevância ideológica e estilística justifica a publicação, "pela primeira vez na íntegra”. São documentos que contribuem "para o melhor conhecimento do clima intelectual (...) entre os nossos ilustrados, ao tempo da regência e do reinado de Dom João". (EULALIO,1964, p.197).

\section{Folhetim}

A publicação de Carranquinhas, de Celso Magalhães ${ }^{l l}$ justifica-se principalmente pelo interesse que nelas desperta a crítica direta dos costumes. A utilização de um disfarce ficcional, representado pelo macaqui-

10 Rio de Janeiro, n. 25, mar.1964, p.191-212.

11 Rio de Janeiro, n. 29/30, 1966, p.97-129. 
nho narrador, vale para o editor como um artifício que provoca um efeito positivo sobre o público, garantindo a intenção educativa e moralizadora do folhetinista.

O editor destaca o retrato pitoresco da antiga São Luís de Celso Magalhães e cita Gilberto Freyre, a propósito das transformações dos costumes registradas nas Carranquinhas.

Os seus comentários [de Celso Magalhães] sobre recentes inovações da vida urbana (..) certamente hão de interessar ao Gilberto Freyre de Ordem e Progresso, enquanto traduzem a imediata compreensão de um radical transformar de costumes de convívio social, que também ali no Maranhão está tendo lugar. (EULALIO, 1966, p.98).

Interessante notar como, através da leitura direcionada às Carranquinhas, avulta a contribuição fundamental não só da imprensa, como também da formação acadêmica: "No roteiro entre a fazenda e a Academia, havia-se formado um homem novo, consciente de sua responsabilidade social. Através do jornalismo ameno, Celso lançava-se numa campanha que pretendia ser moralizadora”. (EULALIO, 1966, p. 99). Ambas as instituições atuam como força geradora do pensamento e da ação interessados na construção de uma sociedade mais civilizada e justa.

Celso Magalhães encarna esse ideal de justiça e - como observa Alexandre Eulalio com base em declaração de Graça Aranha - consolida uma tradição literária calcada na denúncia social, - tarefa que Aluísio Azevedo mostrou mais tarde capaz de exercer, projetando sua obra em escala nacional.

São dados, enfim, que colaboram para fixar o perfil intelectual deste filho da elite maranhense, dono de grande capacidade produtiva nos mais variados gêneros e que se aferra aos princípios ditados pela Escola do Recife. De posse deles, Celso Magalhães abrirá caminho para atuação nos rumos culturais da sua província. E mesmo para além dela, com a criação de estudos no campo do folclore e no da ficção.

\section{HISTÓRIA DOS DOCUMENTOS}

A história dos documentos publicados merece explicação à parte, principalmente quando se trata de rever a passagem de Alexandre Eulalio na Revista do Livro. Considerando o trabalho de edição empreendido pelo autor, a recuperação que promove da obra menor de Joaquim Felício, dispersa no jornal O Jequetinhonha, representa o ponto alto de sua pesquisa documental. Dela temos o seguinte registro: 
A obra menor de Joaquim Felício dos Santos encontra-se, com exceção da Acaiaca, ainda dispersa pelas páginas de $O$ Jequetinhonha. Para o nosso trabalho, servimo-nos de uma coleção existente em Belo Horizonte, conservada por Sílvio Felício dos Santos, e de duas outras, que possui a Biblioteca Nacional, hoje recolhidas à Seção de Obras Raras. Com uma última, recentemente adquirida pelo Museu do Diamante do velho Tijuco, são essas quatro as únicas coleções de O Jequetinhonha de que se tem notícia. (EULALIO, 1993, p.43).

Passamos a mencionar outros exemplos que ilustram a coleção de documentos publicados por Alexandre Eulálio na Revista do Livro. Para avaliar a importância atribuída pelo editor a esses papéis antigos, verificamos o cuidado em recuperar, além do próprio material, as circunstâncias da própria recuperação. São histórias paralelas que se formam, envolvendo os autores, herdeiros, pesquisadores, como ocorre com as "Cartas de Abdir a Irzerumo do Padre Antonio de Sousa Caldas", onde a história se integra à própria origem do documento. Cabe ao editor informar o extravio e consequente desaparecimento de quase todas as cartas, exceto as "cinco peças conservadas num apógrafo datado de fevereiro de 1830, oferecido ao Instituto Histórico e Geográfico Brasileiro". (EULALIO, 1964, p.195).

A pesquisa do crítico passa a confrontar as datas possíveis em que ocorreu a doação dos papéis. Outras hipóteses consideram os motivos do atraso na publicação das "Cartas", em vista do receio quanto ao poder de repercussão delas. As várias possibilidades levantadas permitem ao crítico tecer um quadro de previsões bastante engenhoso, a partir de uma situação misteriosa, em torno de documentos desaparecidos e parcialmente recuperados. Alinhavar as hipóteses representa, para o editor, uma contribuição capaz de estimular novos estudos no terreno da história literária brasileira, tarefa para "o futuro biógrafo de Caldas quando tratar da posteridade da obra do tradutor dos Salmos”. (EULALIO, 1964, p.196).

São várias as curiosidades que envolvem também a publicação das três cartas de Eça de Queirós, endereçadas a Eduardo Prado. Deve-se ao centenário comemorativo do nascimento do escritor paulista, critério do qual Alexandre Eulalio muito se vale ao longo de sua carreira. De volta às cartas, a primeira delas apareceu "estampada em fac-símile por Plínio Barreto na Revista do Brasil, em fevereiro de 1916, numa seleção do epistolário ativo e passivo de Prado que então conservava Edmundo Navarro de Andrade". (EULALIO,1966, p.104).

Quanto às outras, inéditas, foram "gentilmente cedidas à Revista do Livro por Dona Cândida Ferraz Sampaio (nascida Cândido Prado Pacheco e Silva), sobrinha-neta do autor dos Fastos da Ditadura Militar no 
Brasil, e que as conserva zelosamente entre os seus papéis de família”. (EULALIO, 1960, p.104).

Caso que merece a atenção do colecionador de raridade bibliográfica é a conferência de Oliveira Lima sobre Machado de Assis. O editor se volta para as circunstâncias que marcaram a história do documento. Proferida na Sorbonne, em abril de 1909, o texto ganhou versão em português que aparece no ano seguinte, publicada no Jornal do Comércio. Alexandre Eulalio ainda informa a respeito da condição de raridade bibliográfica atribuída ao original em francês.

Os demais exemplos pesquisados confirmam o mesmo empenho de nosso autor em tirar do esquecimento uma documentação dispersa e variada, que inclui desde velhos jornais provincianos a cartas e registros de intelectuais brasileiros importantes.

Lendo o belo ensaio sobre as Carranquinhas de Celso Magalhães, verificamos o empenho em tirar do esquecimento velhos jornais. A pesquisa miúda pode aqui se exercitar plenamente, no interesse de fixar a trajetória do jovem acadêmico e futuro promotor maranhense. Jornais provincianos, revistas acadêmicas surgem em profusão.

Aluno do segundo ano recolhe a produção poética esparsa por revistas e jornais, e publica, na famosa tipografia de Belarmino de Matos, em São Luís, o volume Versos (1867-1870); já antes disso, havia começado a publicar com regularidade nas grandes folhas do Recife - Correio Pernambucano, Jornal do Recife - e ainda em O Paiz do Maranhão. A elas acrescentará, até o fim do período acadêmico, as revistas mais ou menos efêmeras ligadas à Faculdade, como o Outeiro Democrático e O Trabalho, além de uma ou outra gazetas mais modestas de São Luís, como $O$ Domingo. (EULALIO, 1966, p. 100).

Na linha de divulgação de documentos pertencentes a figuras ilustres, encontramos o seguinte comentário do editor:

Assim, regozijamo-nos com a oportunidade de reproduzir aqui uma seleção de cartas existentes no arquivo de Afonso Arinos e que, conservadas pela sua viúva, agora nos foram franqueadas pela gentileza de Dona Cândida Ferraz Sampaio, sobrinha da última. (EULALIO,1959, p.141).

\section{Papéis avulsos de José Veríssimo}

A mesma orientação pode ser avaliada na introdução que Alexandre Eulalio faz a "Papéis avulsos de José Veríssimo"12. Vejamos a seguinte

12 Rio de Janeiro, n.10, jun.1958, p.167-18o. 
declaração do editor: "Continuando a nossa publicação de inéditos de figuras notáveis das nossas letras - o que, digamos de passagem, não é tarefa muito fácil, pois os que os possuem nem sempre se dispõem a franqueá-los..." (EULALIO, 1958, p.167).

Os papéis dizem respeito "a três artigos que deviam ser destinados a $O$ Imparcial", jornal que contou com a colaboração de José Veríssimo de 1912 a 1916, ano de sua morte. A introdução especifica cada um dos artigos: um deles, sobre $A$ chave de Salomão de Gilberto Amado; outro, "de caráter político"; e o último deles sobre os ecos da Guerra Mundial na literatura. Também são objeto da seção "Inéditos", da Revista do Livro, esquemas de capítulos da História da Literatura Brasileira.

\section{Três artigos de Euclides da Cunha}

Com "Euclides, crítico de idéias"13, o editor oferece "três artigos de Euclides da Cunha, esquecidos nas coleções de O Estado de São Paulo, sobre o livro Brasil Mental de Bruno" (EULALIO, 1958, p.183), ensaísta português que adotou esse nome. A nota sublinha o momento da composição dos artigos - junho de 1898 coincidente, portanto, com o início da redação de Os Sertões. O autor do comentário aponta o interesse que o livro de Bruno despertou em Euclides da Cunha, impressão sugerida pela espontaneidade com que formulou os textos. A nota se ocupa em seguida de informar sobre o autor de Brasil Mental e sua obra.

Alexandre Eulalio publica, na Revista do Livro, algumas cartas familiares e outras esparsas de Euclides da Cunha, mantidas "sob a custódia da Seção de Manuscritos da Biblioteca Nacional (...) documentos importantes para se aquilatar uma das mais importantes facetas da vida afetiva de Euclides, pouco conhecida". (EULALIO, 1959, p.77).

Esse lote de cartas aparece em Correspondência de Euclides da Cunha, livro que Walnice Galvão e Oswaldo Galotti organizaram. É possível ler na introdução:

Até a publicação da Obra Completa (1966) pela Aguilar, organizada sob a direção de Afrânio Coutinho, pouca coisa de interessante aconteceu: a de maior relevo é a publicação, pela Revista do Livro (1959), de um punhado de cartas autógrafas encontrado na Biblioteca Nacional. (GALVÃO; GALOTTI, 1997, p.10)

13 Idem, p.183-198. 


\section{COMPROMISSO COM A RECUPERAÇÃO DAS OBRAS}

O critério adotado para a recuperação das obras varia, como temos visto, de acordo com fatores diferentes. Talvez o principal interesse do crítico, em sua atuação na Revista do Livro, obedeça à necessidade de chamar atenção para um trabalho que caberia aos organizadores das obras completas de determinado autor mais importante, como ocorre com Euclides da Cunha, Machado de Assis, José de Alencar. No caso dos escritores secundários, Alexandre Eulalio tende a valorizar as informações históricas e aquelas relativas à história literária. Mas não deixa de sublinhar, quando necessário, qualidade de ordem estética.

Sempre de acordo com o compromisso de sublinhar os elementos vivos de uma obra reconhecidamente secundária, o crítico tende a ultrapassar os limites da informação histórica e reconhecer o valor de outros elementos, o que amplia a importância do documento publicado.

Em relação às Páginas do ano 2000, de Joaquim Felício dos Santos, Alexandre Eulalio considera como autêntico e superior o humorismo e a ironia do historiador diamantino. Em outras palavras, o editor acaba por demonstrar o que é característico na obra examinada, apontando ainda seu lado original e surpreendente, como ocorre nesse texto sobre Joaquim Felício, onde o político cede ao utopista e o jornalista político associa-se ao comediógrafo.

Já o exame da documentação relativa ao arquivo de Afonso Arinos leva o crítico a observar a etapa que antecede à obra pronta, seus andaimes e rascunhos. As anotações e correspondência de Arinos são testemunhos do impacto da vivência na criação artística. As cartas do escritor mineiro relatam a viagem realizada a Diamantina - o que lhe permite "contato direto com o homem e a paisagem em torno dos quais construiu a parte mais importante de sua obra". E, mais do que isto, esclarecem "o método pelo qual o autor (...) recolhia o material de seus contos rústicos (EULALIO, 1959, p.141).

Quanto aos três artigos de Afonso Celso, o crítico estabelece um recorte visando à recuperação memorialística do escritor monarquista, "aquilo que de mais vivo produziu sua pena", merecendo especial destaque a "reportagem evocativa" - exemplo de domínio narrativo, onde desaparecem os enfeites do estilo, recorrentes na produção literária de Afonso Celso, deixando livre o jornalista movido por emoção expressa com sinceridade.

A influência de Celso Magalhães sobre Aluísio Azevedo, conforme afirma Alexandre Eulalio, define uma linha de pesquisa orientada em di- 
reção a obras que contribuíram de modo significativo para alimentar outras obras de maior fôlego. Alexandre Eulalio reforça, desse modo, a importância da tradição, aqui muito bem exemplificada, através da relação entre dois autores de peso diferenciado. Aproximações dessa natureza, segundo o autor, são absolutamente necessárias para o enriquecimento de nossa história literária e cultural.

\section{A COMPOSIÇÃO DOS TEXTOS CRÍTICOS E A ÊNFASE NO RETRATO BIOGRÁFICO}

Atento ao gênero memorialístico e ao apelo da História, o editor redige seus ensaios, artigos e resenhas, de acordo com certos expedientes que auxiliam na tarefa de compreender as cartas, diários, arquivos escolhidos para serem publicados, sobretudo na Revista do Livro.

Um dos procedimentos mais constantes que a escolha dos textos memorialísticos exige é o perfil biográfico ${ }^{14}$. Mesmo quando a experiência de vida não se encontra em primeiro plano, ela surge como uma necessidade colocada pela obra. O exemplo de Celso Magalhães não deixa de ilustrar essa relação. Profundamente integrado a sua São Luís, escreve sem perder de vista a cidade e seus moradores.

O crítico comenta a movimentada vida social do promotor, "com sua ponta de dandy", flor vermelha na botoeira, e grande incentivador da boa música lírica. O gosto em flagrar certas cenas menores leva o editor a reproduzir os comentários do jornal Os Parênteses, sobre os saraus musicais promovidos por Magalhães, chegando mesmo a transcrever o programa de um deles.

A nota final do ensaio confirma a intenção biográfica que anima esse texto sobre As Carranquinhas. Alexandre retrata o episódio dramático que opõe o escritor à sociedade escravocrata da época e acaba por levá-lo à morte. A linha analítica calcada na vida exemplar desse homem tão representativo de sua geração, sobretudo quanto ao empenho entre o ideal

14 Dominique Maingueneau faz o seguinte comentário sobre a pesquisa biográfica: “Cabe então à história literária tecer correspondências entre as fases da criação e os acontecimentos da vida. Na realidade, a obra não está fora de seu contexto biográfico, não é o belo reflexo de eventos independentes dela. Da mesma forma que a literatura participa da sociedade que ela supostamente representa, a obra participa da vida do escritor. O que se deve levar em consideração não é a obra fora da vida, nem a vida fora da obra, mas sua difícil união”. MAINGUENEAU, Dominique. O contexto da obra literária. São Paulo: Martins Fontes, 1995 p.47. 
dela e a compreensão crítica do país, é decisiva para o entendimento da obra apresentada.

O retrato biográfico também ajuda na apresentação dos escritos de Afonso Celso. Comprova a estratégia a utilização de uma pequena biografia e de uma nota final transcrita da Biografia crítica das letras mineiras, livro de Waltensir Dutra e Fausto Cunha. Talvez a natureza memorialística das reportagens exija do editor uma conduta capaz de esclarecer as motivações pessoais de certo autor, publicando-lhe assim a biografia. Sem contar o interesse do historiador em registrar, através dela, os acontecimentos.

Já a composição do estudo que aborda as três cartas de Eça de Queirós apela para um tipo de colagem. À voz em primeira pessoa do missivista soma-se a de outros interlocutores, revistos através de cartas, livros de memórias, ensaios historiográficos e biográficos.

Se o tema da amizade ganha destaque nesse texto de apresentação às cartas, não resta dúvida de que nele surja com igual ou maior clareza o perfil de Eduardo Prado. Ele resulta de uma fina composição do editor literário, que utiliza como fonte de consulta lembranças com forte tonalidade pessoal e familiar: o livro de memória escrito pelos filhos de Eça e as diversas cartas do romancista português enviadas a amigos e pessoas da família.

Através dos relatos colhidos, os fatos narrados criam um clima de intimidade que cerca os dois amigos. Viagens, transtornos domésticos, encontros durante o almoço ou as saídas para jantar, tudo converge para estabelecer um fio narrativo que se acompanha com prazer e curiosidade, graças ao arranjo proposto, bela colagem de trechos de cartas e confissão de caráter memorialístico.

A intenção de traçar o retrato de Eduardo Prado se efetiva com duas outras consultas recortadas de livros não pertencentes ao memorialismo familiar. Alexandre Eulalio recorre ao historiador Otávio Tarquínio de Sousa e a Luís Viana Filho para complementar as explicações de ordem biográfica.

O artigo laudatório que o editor junta ao apêndice da publicação, texto que o romancista consagra ao amigo, é prova da cumplicidade entre esses dois admiradores incondicionais de Eduardo Prado: Alexandre Eulalio e Eça de Queirós. O trabalho de edição, que explica o modo de compor o ensaio eulaliano, completa-se com a apresentação dos próprios documentos. São maneiras encontradas para trazer ao presente "o nome de um autor apreciável [Eduardo Prado], que não poderia ser esquecido na história de nossa cultura”. (EULALIO, 1960, p.108). 
Para tratar de Graça Aranha, o pesquisador prefere os fatos de natureza biográfica, que passam a exercer importante função na estrutura do ensaio, cabendo a eles estabelecer o profundo sentimento da época que a conferência de Graça Aranha serve para evidenciar.

A juventude do escritor maranhense ("ainda não é autor de suas obras"), aliada à disponibilidade com que se encontra em Buenos Aires, correspondem à mesma despretensiosa atenção e simpática receptividade com que é recebido pelos portenhos. Tal estado de espírito auxilia na composição do ensaio: desenho do movimento cultural através das circunstâncias de viagem realizada por um jovem escritor brasileiro.

\section{FAMÍlIAS, PROVÍNCIA E MEMÓRIAS}

Voltando à Revista do Livro, podemos observar como o historiador procura orientar-se segundo alguns parâmetros, certos interesses que sempre se renovam como, por exemplo, aqueles relativos à origem familiar. Os Prados, os Felícios dos Santos, Lúcio e Salvador de Mendonça, Graça Aranha e Celso Magalhães. Relacionada a todas essas famílias e acima delas encontra-se a família imperial, muito bem representada na Revista do Livro pelo príncipe Dom Luís e seu Journal de Guerre.

A escolha pessoal dos autores que o crítico estuda traz, além das opções ideológicas, o espaço geográfico, pois as histórias familiares estão sempre localizadas principalmente na província, se bem que o Rio de Janeiro e alguns países estrangeiros funcionem como um contraponto. A questão espacial é um elemento tão importante na pesquisa de Eulalio quanto o tempo e as pessoas.

Na Revista do Livro, como também em outras publicações em que Alexandre Eulalio escreveu, Diamantina aparece como o ponto central da geografia pessoal alexandrina, e estendendo um pouco mais os limites, temos Minas Gerais. São Luís do Maranhão não deixa de ser outra província de destaque, conforme sugere a presença de Celso Magalhães, Graça Aranha e seu pai e também Aluísio Azevedo.

Outra sugestão que os estudos de Eulalio na Revista do Livro trazem é a preferência por gêneros sintonizados com o memorialismo, como carta, diário, arquivos, ou mesmo aqueles como conferência, artigos de jornal, crônicas. Formas que possibilitam ao historiador da cultura recuperar experiências individuais impregnadas de historicidade. Interessa a nosso autor ver a tensão entre o Brasil Imperial e o Brasil do início da República confrontar-se nos pequenos episódios relatados por personagens maiores ou menores de nossa história cultural. 
A sustentação interpretativa de seus escritos apóia-se, portanto, em exigência menos de caráter estético que histórico, haja vista o caráter fronteiriço ou secundário das obras que Alexandre Eulálio seleciona para estudar.

\section{REFERÊNCIAS BIBLIOGRÁFICAS}

COMPAGNON, Antoine. O demônio da teoria. Literatura e senso comum. Belo Horizonte: Ed. UFMG, 2001.

GALVÃO, Walnice Nogueira; GOTLIB, Nádia (Org). Prezado senhor, prezada senhora: estudo sobre carta. São Paulo: Companhia das Letras, 2000.

EULALIO, Alexandre. Escritos. Organização de Berta Waldman e Luiz Dantas. Campinas: Editora da UNICAMP; São Paulo: Editora UNESP, 1992.

EULALIO, Alexandre. Livro Involuntário: literatura, história, matéria e memória. Organização de Carlos Augusto Calil e Maria Eugênia Boaventura. Rio de Janeiro: Editora UFRJ,1993.

LAFETÁ, João Luiz. Debatedor da palestra: EULALIO, Alexandre. A literatura em Minas Gerais no século XIX. In: EULALIO, Alexandre. Escritos. Berta Waldman; Luiz Dantas (Org). Campinas: Editora da Unicamp, São Paulo: Editora da Unesp, 1992.

MAINGUENEAU, Dominique. O contexto da obra literária. São Paulo: Martins Fontes, 1995.

Remate de Males. Alexandre Eulalio Diletante. Revista do Departamento de Teoria Literária do Instituto de Estudos da Linguagem da UNICAMP. Organizado por Carlos Augusto Calil e Maria Eugênia Boaventura. Campinas, 1993.

Remate de Males. Brito Broca. Vida literária e história cultural. Revista do Departamento de Teoria Literária da Unicamp. (Org.) Francisco Foot Hardman, Campinas, n. 11, 1991.

Revista do Livro. Rio de Janeiro, Instituto Nacional do Livro. Ministério da Educação e Cultura, 1956-1970. 43 volumes. 